\title{
Skin-reducing Mastectomy with Primary Implant Reconstruction
}

\section{Die hautsparende Mastektomie unter Verkleinerung des Hautmantels mit sofortiger Implantatrekonstruktion}

Authors

Affiliations
W. Siggelkow ${ }^{1}$, K. Lübbe ${ }^{1}$, J. Gade ${ }^{1}$, H. Kölbl², M. Schmidt² ${ }^{2}$ D. Böhm²

${ }^{1}$ Gynaecological Hospital, Diakonische Dienste Hannover, Hannover

${ }^{2}$ University Gynaecological Hospital, Johannes-Gutenberg-Universität, Mainz

\section{Key words \\ - gynaecology \\ - breast \\ - breast cancer \\ Schlüsselwörter \\ - Gynäkologie \\ - Mamma \\ - Mammakarzinom}

received $\quad 4.12 .2011$

revised $\quad 9.4 .2012$

accepted 10.4.2012

Bibliography

DOI http://dx.doi.org/

10.1055/s-0032-1315120

Geburtsh Frauenheilk 2012; 72 :

616-621 @ Georg Thieme

Verlag KG Stuttgart · New York . ISSN 0016-5751

\section{Correspondence}

Wulf Siggelkow, M. D.

Diakonische Dienste Hannover Frauenklinik

Schwemann Straße 17

30559 Hannover

wulf.siggelkow@ddh-gruppe.de

\section{Abstract \\ V}

Background: We present a series of skin-sparing mastectomies (SSMs) with skin reduction and immediate breast reconstruction to treat large and ptotic breasts. The technique combines oncological mastectomy with immediate subpectoral implant placement as a single-step procedure. Methods: Data was collected from a prospective database from February 2009 to April 2011. A total of 24 patients with macromastia or pronounced ptosis fulfilled the criteria for skin-saving mastectomy. All operations were carried out as a single-step procedure with adaptation of the contralateral breast by reduction mastopexy.

Results: A total of 27 SSMs were performed in 24 patients. The mean implant volume was $265 \mathrm{~cm}^{3}$. Immediate reconstruction of the nipple-areola complex was done in 22 patients. The cosmetic and functional results were assessed in all patients 6 months postoperatively; mean follow-up time was 13 months. Mean patient age was 49 years. The cosmetic result was assessed as "very good" or "good" by 22 patients; 2 patients graded the result as "unsatisfactory". There was one local recurrence.

Conclusion: Our results support the use of this technique as a safe oncoplastic procedure which is well tolerated by patients.

\section{Zusammenfassung \\ $\nabla$}

Hintergrund: Wir stellen die Ergebnisse einer Serie hautsparender Mastektomien mit Verkleinerung des Hautmantels und Sofortrekonstruktion für größere und ptotische Brüste vor. Diese ermöglicht in einer einzeitigen Operation sowohl eine onkologisch sichere Mastektomie wie auch eine sofortige implantatgestützte Wiederherstellung der Brust.

Methoden: Wir präsentieren Daten einer prospektiven Datenbank unserer Kliniken von Februar 2009 bis April 2011. Insgesamt erfüllen 24 Patientinnen die Kriterien einer hautsparenden Mastektomie bei gleichzeitig bestehender Makromastie bzw. ausgeprägter Ptosis. Alle Operationen wurden unter Angleichung der Gegenseite mittels einer zentrokaudalen Reduktionsmastopexie einzeitig durchgeführt.

Ergebnis: Es werden 27 hautsparende Mastektomien mit Implantat-Sofortrekonstruktion in 24 Patientinnen ausgewertet. Das durchschnittliche Implantatvolumen betrug $265 \mathrm{~cm}^{3}$. In 22 Patientinnen erfolgte eine Sofortrekonstruktion des Nippel-/Areolakomplexes. Eine Erfassung des kosmetischen und funktionellen Ergebnisses erfolgte bei allen Patientinnen 6 Monate nach OP, die mediane Nachbeobachtungszeit lag bei 13 Monaten. Das durchschnittliche Alter der Patientinnen lag bei 49 Jahren. Das kosmetische Ergebnis wurde von 22 Patientinnen als sehr gut bzw. gut empfunden, 2 Patientinnen empfanden das Ergebnis als unzulänglich. Es trat ein Lokalrezidiv im Hautweichteilmantel auf.

Zusammenfassung: Im Ergebnis unserer Untersuchung ist die hautsparende Mastektomie unter Verkleinerung des Hautmantels mit einzeitiger Implantatrekonstruktion ein sicheres und von den Patientinnen gut akzeptiertes Verfahren. 


\section{Introduction}

$\nabla$

Skin-saving mastectomy with reduction of the skin envelope covering the reconstruction is considered a technically and oncologically safe procedure [1-5]. The technique does not result in an increase in local recurrence [6,7]. Moreover, immediate breast reconstruction does not lead to a delay in the delivery of adjuvant therapy [8].

Preserving the skin and the inframammary fold, when done as an immediate reconstruction plasty, improves the reconstructive result and minimises surgical scarring. Implant reconstruction can be done either through subcutaneous or subpectoral implant insertion. The former technique results in a good shape and ptosis but is attended by the disadvantage of thinner skin over the implant as well as an increased incidence of skin necroses, implant perforation, implant migration and higher rates of capsular contractures [9-11].

The acceptance of submuscular prostheses has increased as the skin covering of implants has improved and implant-associated complications have decreased. One of the problems with this technique is achieving proper volume and contouring of the lower breast pole [12].

Skin-saving mastectomy with reduction of the skin permits the additional creation of a caudal, dermal flap, which in connection with the use of the lower edge of the pectoralis muscle, ensures complete coverage of the implant and adequate volume of the lower breast pole [13].

The aim of this study was to collect data on the functional and cosmetic results after skin-saving reduction mastectomy with immediate reconstruction using implants and adaptation of the contralateral breast in patients with macromastia or pronounced ptosis. The typical early complications of this technique are discussed.

\section{Methods}

In the period from February 2009 to April 2011 we compiled a consecutive database of 24 women treated in the gynaecological clinics of the Diakonische Dienste Hanover (Diakoniekrankenhaus Friederikenstift, Diakoniekrankenhaus Henriettenstiftung). Mean follow-up time of patients was 13 months. Patient satisfaction with the functional and cosmetic outcome was recorded for all patients 6 months postoperatively based on questions put to patients by the surgeon using a questionnaire. The questionnaire evaluated patient satisfaction with the breast reconstruction, the information given about existing alternatives and patient satisfaction with bilateral volume reduction.

This study focused on patients with symptomatic macromastia as well as patients with mastoptosis. All patients recorded in the study fulfilled the oncological criteria for skin-saving mastectomy. All patients with indications for post-mastectomy radiation were excluded preoperatively. The maximum clinical tumour size was $3 \mathrm{~cm}$. Eight patients with multicentric breast cancer without skin involvement, 9 patients with extensive intraductal tumour components (extent of microcalcification on mammography $>4 \mathrm{~cm}$ ) and 4 patients who undergone previous neoadjuvant chemotherapy were recruited into the study. Prior to neoadjuvant chemotherapy the 4 patients were considered unsuitable for breastsaving therapy for oncological reasons. Three patients underwent bilateral skin-saving mastectomy with reduction of the skin covering and immediate implant reconstruction for prophylactic

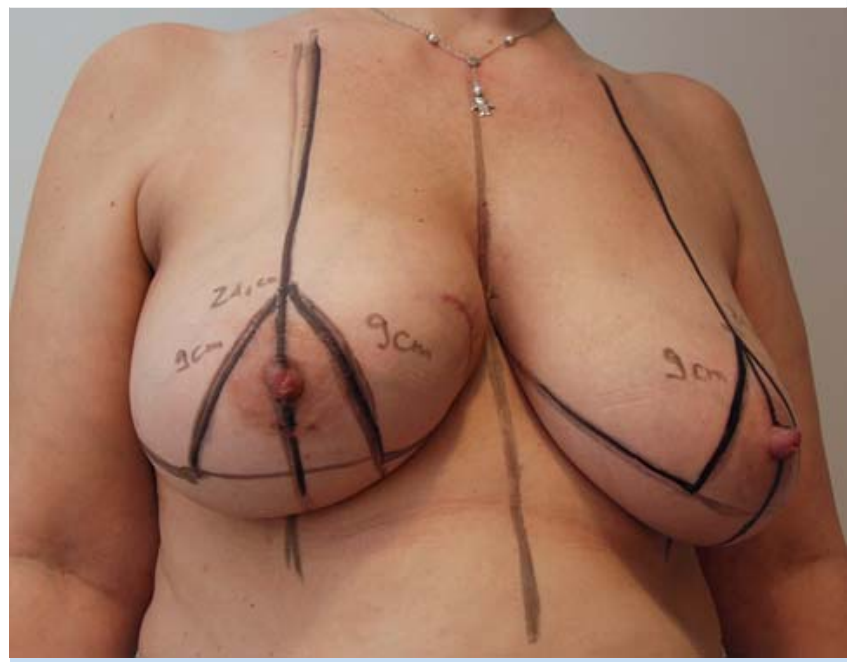

Fig. 1 Marking done with the patient in a standing position. Marking for segmental resection in the inner lower right quadrant with a $5 \mathrm{~cm}$, highgrade circumscribed ductal carcinoma in situ.

indications. Patients in whom the length between nipple and submammary fold was more than $10 \mathrm{~cm}$ and the length between sternum and nipple was more than $24 \mathrm{~cm}$ were considered suitable. All surgical procedures were carried out concomitantly with centro-caudal reduction mastopexy of the contralateral breast to adapt the size of the contralateral breast in a single-step procedure. All surgical procedures described in this study were done by the same main surgeon (W.S.). No patient required radiation postoperatively.

\section{Operative Procedure \\ $\nabla$}

\section{Preoperative Marking}

Marking of the breasts is done in all patients the evening before the surgical procedure with the patients awake and in a standing position ( Fig. 1). The marking corresponds to the procedure used for centro-caudal reduction mastopexy where the tips of the cranially inverted Vs on both sides mark the new position of the nipple. The length along one side of the inverted $\mathrm{V}$ from the centre of the new nipple to the new submammary fold is around $9 \mathrm{~cm}$. The diagonal skin area caudal to the side of the inverted $\mathrm{V}$ on the reconstruction side is used as an inferior dermal flap; on the reconstruction side this area corresponds to the future centro-caudal nipple pedicle.

\section{Implants}

All implants used were obtained from Mentor Germany (Hallbergmoos, Germany). The volume of the implants used on the reconstruction side ranged from 140 to $375 \mathrm{~cm}^{3}$. The mean implant size was $265 \mathrm{~cm}^{3}$. Only anatomically shaped implants were used.

\section{Operative Technique}

Surgery is started on the side of the breast requiring reconstruction. The caudal area underneath the inverted $\mathrm{V}$ is de-epithelialised along the full length of the submammary fold ( $\bullet$ Fig. 2 ). This area is then dissected from the inferior area of the mammary gland with a layer thickness of $0.5-1 \mathrm{~cm}$ ( Fig. 3). Finally an incision is made along the outline of the cranially inverted V. If nip- 


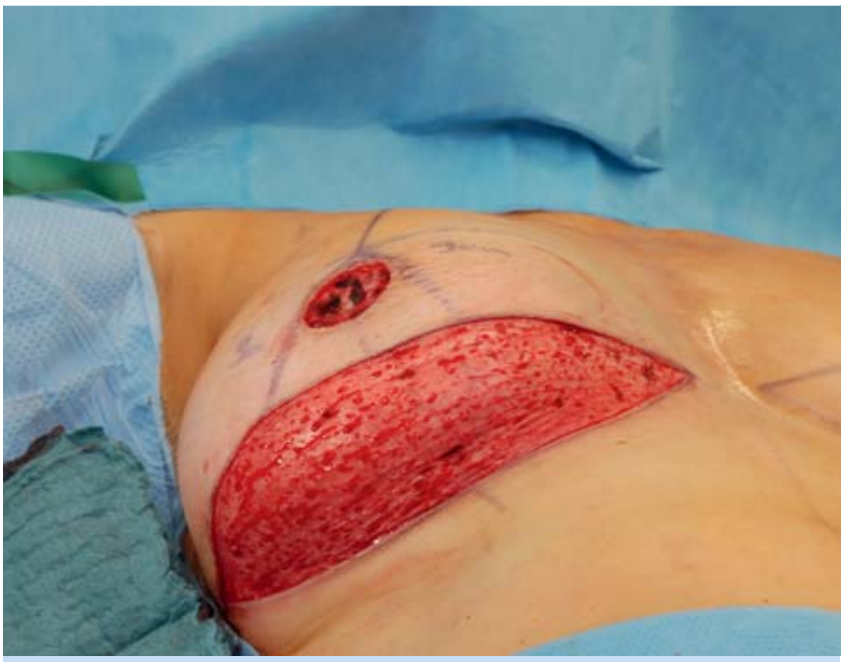

Fig. 2 De-epithelialisation of the caudal dermal flap.

ple reconstruction is planned, this is excised as a full-thickness graft with a defined diameter and preserved. Interfascial resection of the mammary gland from the remaining cranial epidermis is performed. The aim is to achieve complete resection of all parts of the mammary gland, leaving only the skin and subcutaneous fatty tissue ( Fig. 4). This is followed by mobilisation of the pectoral muscle starting from the lateral side, inferiorly and medially up to the 3 o'clock position. Depending on the planned implant size, a temporary implant is placed at the thoracic wall and the inferior edge of the pectoralis major is sewn to the cranial edge of the de-epithelialised epidermal flap ( Fig. 5). The use of a temporary implant allows optimal filling and size of the implant pocket to be ascertained. Finally the cranial epidermis is closed over the submammary fold. All implant reconstruction stages are done with the patient sitting almost upright; a suction drainage is placed. If nipple reconstruction is planned, the position of the nipple is measured from the submammary fold, deepithelialised, and the thinned full-thickness graft of the areola is transplanted. Reduction of the contralateral breast is done

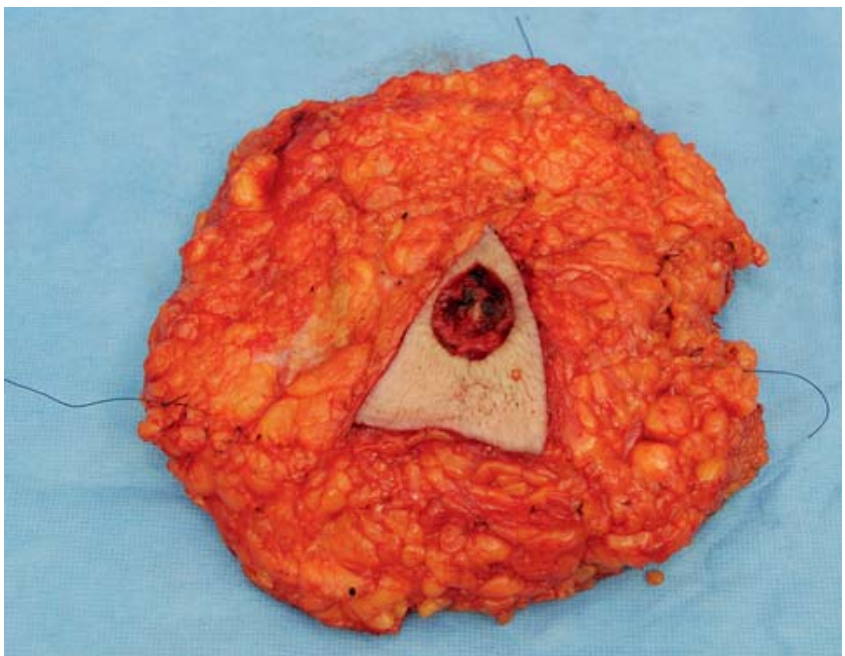

Fig. 4 Resected mammary gland with inverted "V" and areola resected at skin level. Resection diameter: $42 \mathrm{~mm}$.

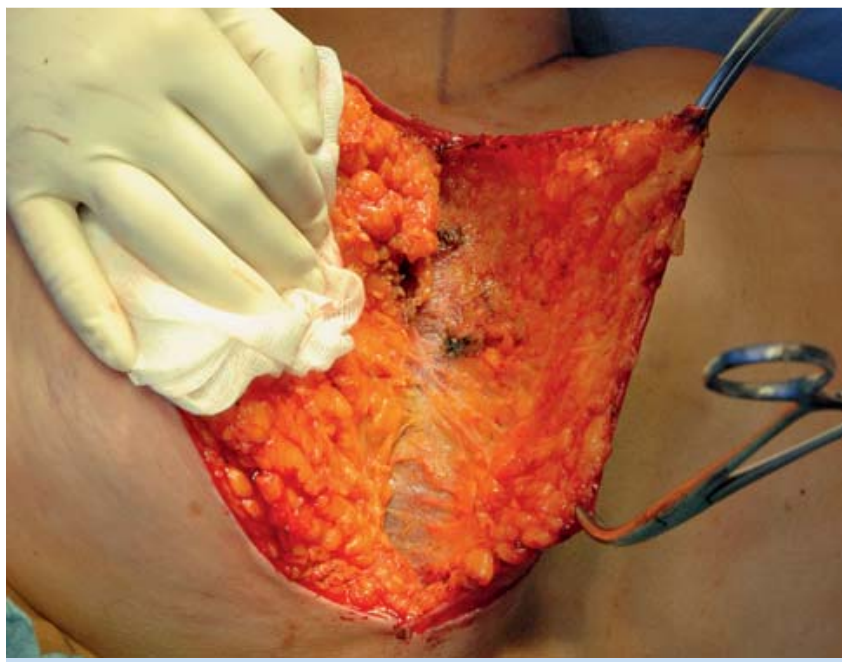

Fig. 3 Resection of the caudal dermal flap from the mammary gland (on the left).

using a standard centro-caudal reduction mastopexy until it matches the shape and size of the reconstructed breast. If sentinel lymph node biopsy is indicated on the reconstruction side, this is done during the procedure described above without an additional axillary incision.

If the planned size of the reconstructed breast cannot be achieved using the planned implant volume in the skin-muscle flap pocket, an expander or permanent expander can be placed as an alternative to placing an implant.

\section{Postoperative procedure}

To optimise lymph flow from the skin envelope and avoid implant displacement, all patients were fitted on the day of operation with a close-fitting sports bra and surgical compression bra. The positioning of these aids was checked by the surgeon on the evening of the operation. Antibiotics were administered during the surgical procedure and postoperatively until the drain next to the implant was removed. Freely transplanted nipples were covered by a compression dressing for 5 days.

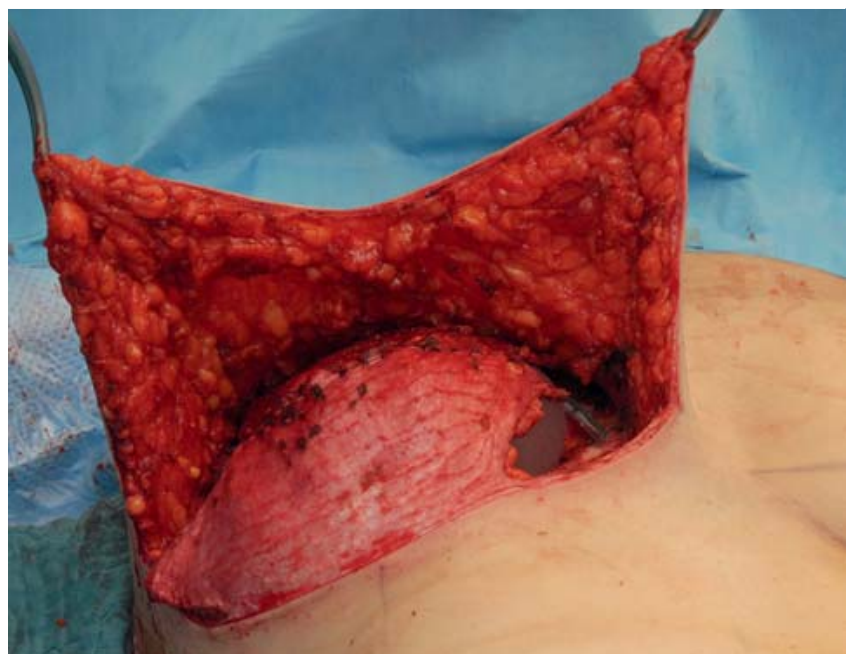

Fig. 5 Closure of the dermal flap (caudal) with mobilisation of the pectoralis major (cranial) over the final implant. 


\section{Results}

\section{$\nabla$}

A total of 27 skin-saving mastectomies with reduction of the skin envelope and immediate implant reconstruction were done in 24 patients. Mean patient age was 49 years (range: 34-69 years); 6 patients were smokers ( $>10$ cigarettes per day). In 21 patients, sentinel lymph node removal was done concomitantly with the surgical procedure. R0 resection of invasive and intraductal tumour components was achieved in all patients during skinsaving mastectomy. One patient had invasive recurrence in the subcutis at 8 months after surgery, which was treated by complete removal of the remaining skin envelope and the implant at the patient's request. None of the patients underwent adjuvant radiation therapy. Twelve patients received endocrine therapy and 8 patients underwent chemotherapy. The mean operative time was 205 minutes (183-265 min).

Early postoperative complications consisted of one implant displacement requiring revision despite adequate use of aids. Small areas of skin necrosis on the reconstructed or reduced breast were recorded in 3 patients. All of these necroses occurred in the T-suture closing the cranial epidermis over the submammary fold and healed spontaneously. There was no clinical evidence of any infection in the implant pocket.

At follow-up after 6 months to evaluate functional and cosmetic results 9 patients described the cosmetic and functional result as "very good" and 13 patients described the result as "good". Two patients described the result as "unsatisfactory". These 2 patients presented with incipient capsular fibrosis and implant dislocation, reduced sensation of the skin in individual areas, and postoperative asymmetry between the reconstructed and the matched breast. The patients are scheduled to undergo corrective surgery for secondary ptosis. No functional or physical impairments were recorded, in particular there was no restriction in the motion of the arms. A total of 23 out of 24 patients would choose to undergo the operation again.

Long-term complications included 2 incipient capsular fibroses (> Baker II). No revision has yet been done in these patients. A more frequent complication was secondary asymmetry with a dissimilar appearance between the reconstructed and the adapted contralateral breast with regard to breast volume and shape. Secondary asymmetry occurred in 3 cases due to ptosis of the contralateral breast treated by mastopexy. When asymmetry was the only complication, the functional/cosmetic result was consistently rated by the patients as very good or good ( Table 1 ).

\section{Discussion}

\section{$\nabla$}

The number of operations performed for breast reconstruction has increased in parallel to the annual incidence rates for breast cancer. This development is also mirrored by an increasing demand for prophylactic and risk-reducing operations [14]. Although implant-based reconstructions still predominate, the few existing long-term studies report high local complication rates of up to $23 \%$ for unilateral and up to $28 \%$ for bilateral operations [15]. The success of future implant materials and operative techniques will be measured by the reduction of local complication rates.

The concept of a skin-saving mastectomy procedure with concomitant or secondary reconstruction of the breast was first described by Toth and Lappert [16]. The volume published by Bostwick in 1990 also refers to the use of skin-sparing mastectomy
Table 1 Complications according to their location.

\begin{tabular}{|c|c|c|}
\hline Complication & $\begin{array}{l}\text { Reduction mastec- } \\
\text { tomy with implant } \\
\text { reconstruction }\end{array}$ & $\begin{array}{l}\text { Adaptive centro- } \\
\text { caudal reduction } \\
\text { mastopexy }\end{array}$ \\
\hline $\begin{array}{l}\text { Capsular contracture } \\
\text { (> Baker II) }\end{array}$ & 2 & $x$ \\
\hline Trophic skin defects & 1 & 2 \\
\hline Implant displacement & 1 & $x$ \\
\hline Asymmetry & $x$ & 3 (secondary) \\
\hline
\end{tabular}

procedure for breast cancer prophylaxis [17]. Use of the technique described here to treat breast cancer was first described by Hammond as a 2-stage operative procedure [11].

A number of studies have proven the oncological safety of skinsaving and nipple-preserving mastectomies [1-3]. Patients with smaller sized breasts can treated without any problems by periareolar or submammary mastectomy, using either implants or expanders, and partial retropectoral implant reconstruction without changing the shape of the breast [2-5]. Larger breasts or extremely ptotic breasts require different procedures to reduce the skin envelope in skin-sparing mastectomy procedures if immediate reconstruction is planned. The contralateral breast must be adapted to achieve symmetry [13].

Although this operative technique is becoming increasingly accepted all over the world, there are only a few studies with limited patient numbers which describe the experience with and complications of this method. Nava et al. published a series of 30 cases of skin-saving mastectomies performed in 28 patients; the majority of these patients had early or early-stage invasive tumours or carcinoma in situ. The study reported the occurrence of skin necroses in $13 \%$ of cases requiring removal of implants over a follow-up period of 14 months. There were no cases of capsular fibrosis [18]. Another study of 18 patients with a comparable range of indications was presented by Querci della Rovere. In this study, one patient required implant removal [12]. In contrast to the report by Nava, tissue expanders were initially used in this study. This allowed secondary adaptation to the target volume with stepwise expansion of the epidermis, resulting in a distinctly lower risk of skin necrosis. The mean follow-up in this study was 26 months. None of the patients in either of the studies required adjuvant radiation therapy.

The technique described here of reducing the skin cover in the breast requiring reconstruction with creation of a caudal dermal flap allows the implant to be completely covered by a skinmuscle layer.

Due to the limited number of cases described in previous studies it is not clear whether a more optimal covering of the implant by an additional caudal dermal flap can reduce the rate of capsular fibrosis compared to partial retropectoral implant positioning. The data were confirmed based on a longer follow-up recorded in a continuous database. Creation of a complete skin-muscle flap allows the implant to be positioned within the patient's own tissue without a transplant operation. A number of publications have indicated that there is a correlation between optimal covering of the implant and fewer local complications [12,14].

Advanced tumour stages require adjuvant radiation therapy after mastectomy and immediate breast reconstruction, depending on the tumour stage and the number of lymph nodes affected, and the local rate of complications increases significantly. In a report by Prabhu et al. [19], the rate of complications in patients with 
tumour stages > pT3 who underwent skin-saving mastectomy with immediate reconstruction and adjuvant radiation therapy was $37 \%$. The main complications reported in this series were infections (41\%), skin necroses (29\%) and wound dehiscence (18\%). The use of the patient's own tissue for reconstruction together with adjuvant radiation led to a reduction of complications. Heitmann et al. [20] presented a study of 8 patients with locally advanced tumour stages who were successfully treated by DIEP flap-plasty.

In our study, all cases with individual areas of necrosis of the skin cover were treated conservatively; the implant pocket was never opened as it was completely covered by the patient's own tissue. We did not require implants with volumes of more than $400 \mathrm{~cm}^{3}$ even to treat patients with extensive macromastia and very large breasts ( Figs. 6 and 7). If simultaneous reduction mastopexy of the contralateral breast is carried out to achieve symmetry, significant volume reduction of both breasts will improve any orthopaedic symptoms.

Secondary asymmetry was an important and not previously published problem in our patient series. In all cases the primary operation achieved optimal symmetry between the breast treated by skin-saving mastectomy and primary implant reconstruction and the contralateral breast treated by adaptive reduction mastopexy. Asymmetry occurred in 3 cases as a secondary outcome. The problem was caused by secondary loss of volume and secondary ptosis. These secondary changes resulted from the difference in consistency and structure between the reconstructed breast and the adapted breast. In this study we overcorrected the position of the nipple in the adapted breast by $1-2 \mathrm{~cm}$. During follow-up, visible glandular and areolar ptosis occurred over the nipple and in the caudal breast volume of the reconstructed contralateral breast, depending on the consistency of the skin and connective tissue. A more extensive individual adaptation which takes account of skin elasticity is necessary for the adapted breast.

An acellular tissue matrix currently being developed by a number of different manufacturers is a new option to improve implant covering [21]. The tissue matrix is versatile but still very expensive and use of the tissue matrix needs to be agreed upon in individual cases with the health insurance company.

Cost is an important aspect of one-stage reconstruction with simultaneous adaptation of the contralateral breast. Classification is done using the ICD-10 (GM2012): C50.8 (malignant neoplasia of the mammary gland, overlapping lesion of the breast) and N62 (breast hypertrophy).

Procedures are classified as 5-877.12 (subcutaneous mastectomy and skin-saving mastectomy procedure: skin-saving mastectomy [SSM] with complete resection of the mammary gland: with tightening of the skin cover and creation of a stalked corium cutis flap), 5-886.40 (other plasty reconstructions of the breast: primary reconstruction with alloprothesis, subpectoral: without tissue reinforcing material) and 5-884.2 (breast reduction plasty: with stalked nipple transplant). Using the 2012 coding for surgical interventions and procedures, a one-stage procedure with an in-hospital stay ranging between the lower length of stay ( 3 days) and the upper length of stay (13 days) results in costs of $5844.55 €$. We carry out the operation only as a one-stage procedure [22].

In summary, skin-saving mastectomy with reduction of the skin envelope, immediate reconstruction and concomitant reduction of the contralateral breast is a safe method which offers good functional and cosmetic results. There were only a few early com-

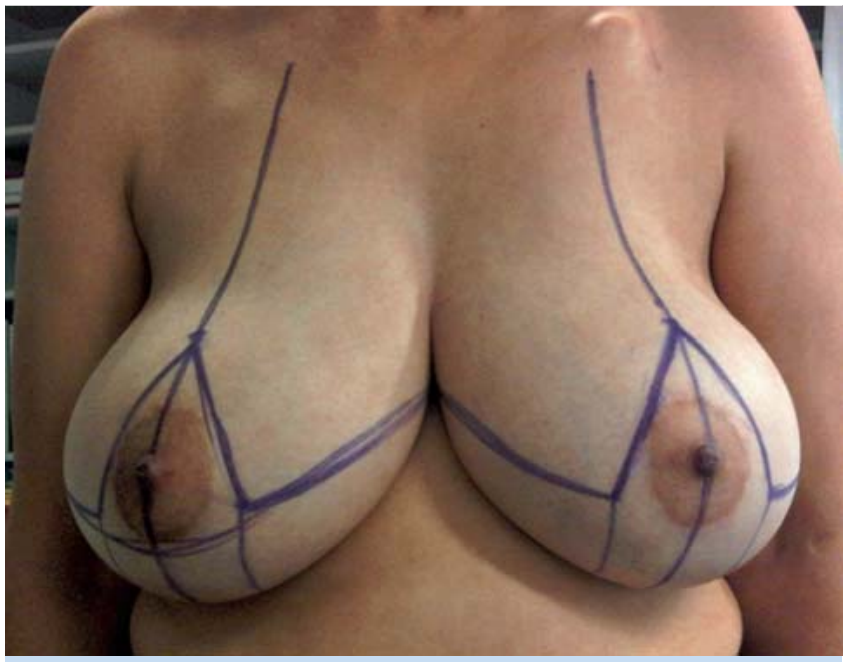

Fig. 6 Patient with extensive symptomatic macromastia and large highgrade ductal carcinoma in situ $(>5 \mathrm{~cm})$ and invasive tumour in the right breast.

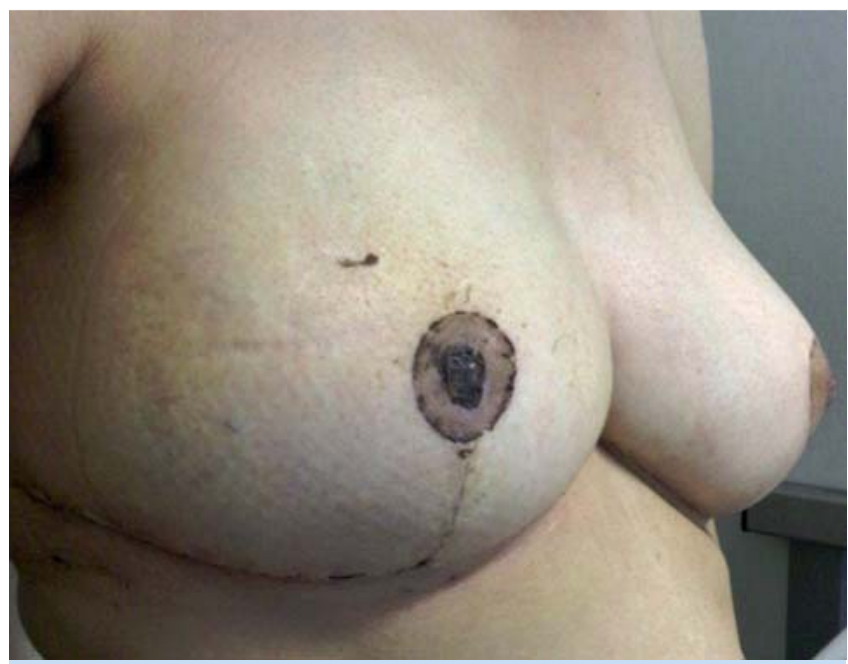

Fig. 7 Postoperative appearance of the right breast after skin-saving mastectomy, reduction of the skin envelope, sentinel lymph node biopsy and primary implant reconstruction. The nipple-areola complex was freely transplanted. The left breast was adapted by centro-caudal reduction mastopexy.

plications in our study. The method is particularly suitable to treat patients with very large or ptotic breasts and early multicentric or intraductal tumour or for breast cancer prophylaxis. With the exception of slight complications such as small patches of skin necrosis, only 2 patients (5\%) experienced therapy-relevant local complications which reduced patient satisfaction with the outcome. The occurrence of secondary asymmetry in our study requires further methodological consideration of the anticipated overcorrection of the nipple position on the adapted breast. Even if patient satisfaction was not influenced by this asymmetry, it affected $7 \%$ of patients in our study.

We restricted the use of this operative technique to patients who did not require radiation therapy of the breast after skin-saving mastectomy. 


\section{Conflict of Interest}

$\nabla$

None.

\section{References}

1 Kroll SS, Khoo A, Singletary SE et al. Local recurrence risk after skinsparing and conventional mastectomy: A 6-year follow-up. Plast Reconstr Surg 1999; 104: 421-425

2 Slavin SA, Schnitt SJ, Duda RB et al. Skin-sparing mastectomy and immediate reconstruction: Oncologic risks and aesthetic results in patients with early-stage breast cancer. Plast Reconstr Surg 1998; 102: 49-62

3 Rivadeneira DE, Simmons RM, Fish SK et al. Skin-sparing mastectomy with immediate breast reconstruction: A critical analysis of local recurrence. Cancer J 2000; 6: 331-335

4 Simmons RM, Fish SK, Gayle L et al. Local and distant recurrence rates in skin-sparing mastectomies compared with non-skin-sparing mastectomies. Ann Surg Oncol 1999; 6: 676-681

5 Medina-Franco H, Vasconez LO, Fix RJ et al. Factors associated with local recurrence after skin-sparing mastectomy and immediate breast reconstruction for invasive breast cancer. Ann Surg 2002; 235: 814-817

6 Newman LA, Kuerer HM, Hunt KK et al. Feasibility of immediate breast reconstruction for locally advanced breast cancer. Ann Surg Oncol 1999; 6: 671-675

7 Langstein HN, Cheng MH, Singletary SE et al. Breast cancer recurrence after immediate reconstruction: patterns and significance. Plast Reconstr Surg 2003; 111: 712-720

8 Wilson CR, Brown IM, Weiller-Mithoff E et al. Immediate breast reconstruction does not lead to a delay in the delivery of adjuvant chemotherapy. Eur J Surg Oncol 2004; 30: 624-627

9 Nahai F, Bostwick J 3rd. Aesthetic aspects of breast reconstruction. Aesthetic Plast Surg 1982; 6: 61-67

10 Eskenazi LB. New options for immediate reconstruction: achieving optimal results with adjustable implants in a single stage. Plast Reconstr Surg 2007; 119: 28-37
11 Hammond DC, Capraro PA, Ozolins EB et al. Use of a skin-sparing reduction pattern to create a combination skin-muscle flap pocket in immediate breast reconstruction. Plast Reconstr Surg 2002; 110: 206-211

12 Querci della Rovere G, Greco M, Nava M et al. Skin-sparing and skin-reducing mastectomy. In: Querci della Rovere G, Benson JR, Breach N, Nava M, eds. Oncoplastic and Reconstructive Surgery of the Breast. 1st edition. London: Taylor and Francis; 2004: 21-31

13 Nair A, Jaleel S, Abott $N$ et al. Skin-reducing mastectomy with immediate implant reconstruction as an indispensable tool in the provision of oncoplastic breast services. Ann Surg Oncol 2010; 17: 2480-2485

14 Baxter NN, Virnig BA, Durham SB et al. Trends in the treatment of ductal carcinoma in situ of the breast. J Natl Cancer Inst 2004; 96: 443-448

15 Craft RO, Colakoglu S, Curtis MS et al. Patient satisfaction in unilateral and bilateral breast reconstruction. Plast Reconstr Surg 2011; 127: 1417-1424

16 Toth BA, Lappert P. Modified skin incisions for mastectomy: The need for plastic surgical input in preoperative planning. Plast Reconstr Surg 1991; 87: 1048-1052

17 Bostwick J Total mastectomy with breast skin and volume reduction using an inverted T incision. In: Bostwick J, ed. Plastic and Reconstructive Breast Surgery. Vol.2. 1st edition. St. Louis, MO: Quality Medical Publishing; 1990: 1048-1054

18 Nava MB, Cortinovis $U$, Ottolenghi J et al. Skin-reducing mastectomy. Plast Reconstr Surg 2006; 118: 603-610

19 Prabhu R, Godette K, Carlson G et al. The impact of skin-sparing-mastectomy with immediate reconstruction in patients with stage III breast cancer treated with neoadjuvant chemotherapy and postmastectomy radiation. Int J Radiation Oncol Biol Phys 2012; 82: 587-593

20 Heitmann C, Schmiel M, Richter-Heine I et al. Plastisch-Chirurgische Versorgung des fortgeschrittenen Mammakarzinoms. Geburtsh Frauenheilk 2010; 70: 994-997

21 Katerinaki E, Zanetto U, Sterne GD. Histological appearance of Strattice tissue matrix used in breast reconstruction. J Plast Reconstr Aesthet Surg 2010; 63: 840-841

22 Graubner B, Hrsg. OPS2012 Alphabetisches Verzeichnis. Operationenund Prozedurenschlüssel - Internationale Klassifikation der Prozeduren in der Medizin. Version 2012. Köln: Deutscher Ärzteverlag; 2012: 536-538

Deutschsprachige Zusatzinformationen online abrufbar unter: www.thieme-connect.de/ejournals/toc/gebfra. 